\title{
Madame Bovary (Señora vaca) o de cómo exponer las representaciones obsoletas de, y en el teatro mexicano
}

El ejemplo del colectivo Teatro sin teatro

\section{Víctor Gabriel Villanueva Pérez}

\section{CpenEdition}

\section{Journals}

Edición electrónica

URL: http://journals.openedition.org/agedor/5167

DOI: $10.4000 /$ agedor.5167

ISSN: 2104-3353

Editor

Laboratoire LISAA

Referencia electrónica

Víctor Gabriel Villanueva Pérez, « Madame Bovary (Señora vaca) o de cómo exponer las

representaciones obsoletas de, y en el teatro mexicano ", L'Âge d'or [En línea], 12 | 2019, Publicado el 01 octubre 2020, consultado el 14 octubre 2020. URL : http://journals.openedition.org/agedor/5167 DOI : https://doi.org/10.4000/agedor.5167

Este documento fue generado automáticamente el 14 octubre 2020.

L'Âge d'or. Images dans le monde ibérique et ibéricoaméricain 


\section{Madame Bovary (Señora vaca) o de cómo exponer las representaciones obsoletas de, y en el teatro mexicano}

El ejemplo del colectivo Teatro sin teatro

Víctor Gabriel Villanueva Pérez

1 Sabemos que las representaciones sociales son necesarias para la sociedad, E. Said nos propone, incluso, que pueden ser tan necesarias como el lenguaje ${ }^{1}$. Sabemos también que dichas representaciones pueden tener diversas funciones dependiendo de la utilización que les designemos y estas pueden ser cognitivas, interpretativas, comportamentales, identitarias, etc. Lo que nos va a interesar exponer en este trabajo es la percepción de dichas representaciones en un dispositivo preciso: el de la comunidad teatral en México.

2 En México, a finales de los años ochenta, se crea la institución del Fondo Nacional para la Cultura y las Artes, esta institución será nuestro punto de enfoque en cuanto a representación colectiva. Expondremos la necesidad de dicha institución en su tiempo y la utilización de ella misma ahora.

Lo que conlleva dicha institución son diferentes capas de representaciones, en primer lugar, es la representación de una necesidad (vuelta institución) por parte de un colectivo, seguida de la representación colectiva que la institución tiene de los grupos artísticos contemporáneos y finalmente encontramos la de la representación teatral.

4 En este artículo nos daremos la tarea de exponer esto desde el punto de vista de la representación teatral, su discurso, su propósito y su reflejo de lo que está representando de la realidad. Nuestro análisis utilizará como recurso el análisis de ciertos aspectos de un espectáculo que se presta por su naturaleza a hablar de ello pues, desde su creación hasta la puesta en escena, expone dichas representaciones sociales. 
5 De esta manera nuestro análisis nos llevará a hablar de las representaciones que en algún momento fueron la necesidad de algunos cuantos y las cuales se volvieron institución para todos. De esta manera podremos cuestionarnos acerca de la caducidad de estos sistemas de poder y de la correlación entre la representación colectiva que en este caso será el Fondo Nacional para la Cultura y las Artes (FONCA) y la representación teatral.

6 Comenzaremos por exponer cómo el colectivo Teatro sin teatro fue creado, bajo qué circunstancias y cómo estas circunstancias particulares darían como resultado la creación del espectáculo Madame Bovary (Señora vaca). Destacaremos las características principales de este espectáculo, las cuales nos ayudarán a reflexionar sobre nuestra idea principal. Seguido de esto, hablaremos de la crisis de las representaciones y de la posible caducidad de estas, en donde expondremos la relación entre la institución gubernamental que de cierta manera rige al teatro mexicano y de la crisis de la representación teatral.

\section{Colectivo Teatro sin teatro}

7 El colectivo Teatro sin teatro es dirigido por José Antonio Cordero, quien paralelamente a su labor como artista escénico y audiovisual, participa entre los años 2008 y 2013 en movimientos y grupos de crítica, reflexión e impulso a las políticas culturales de las artes en México. Es gracias a esta experiencia que comienza a interesarse en transferir lo político-institucional a lo artístico-comunitario. La creación de dicho colectivo comienza a mediados del año 2015, cuando José Antonio Cordero publica en las redes sociales una convocatoria redactada casi telegráficamente, a manera de un "meme" de internet, en la que podemos leer lo siguiente: "Actrices y actores de cualquier edad (currículo innecesario) para puesta en escena sin texto, sin presupuesto, sin teatro" (Ilustración 1). Redactado casi telegráficamente, a manera de un "meme" de internet.

La convocatoria ya es una ironía de lo que la comunidad teatral padece en gran parte de proyectos independientes, sólo que en este caso esa ambigüedad tiene como función convertirse por sí misma en un filtro ideológico. Pues presupone que aquellos quienes respondan a la convocatoria serán principalmente actores y actrices interesados en realizar un proyecto sin contenido en apariencia De esta manera, José Antonio Cordero, logra oponerse a los modos de producción teatrales convencionales, los cuales, generalmente, giran en torno a un texto, un autor, un teatro o un actor (con una carrera suficientemente reconocida o popular) y al presupuesto provisional. De esta forma, el filtro ideológico impuesto por el director de la obra funciona como un llamado a todos aquellos que estén dispuestos a hacer algo fuera del formato y de las redes convencionales. Esto tendrá como consecuencia conformar un grupo de creación escénica el cual, en principio no tendría remuneración, es decir, se desvincularía de la economía teatral institucional. 


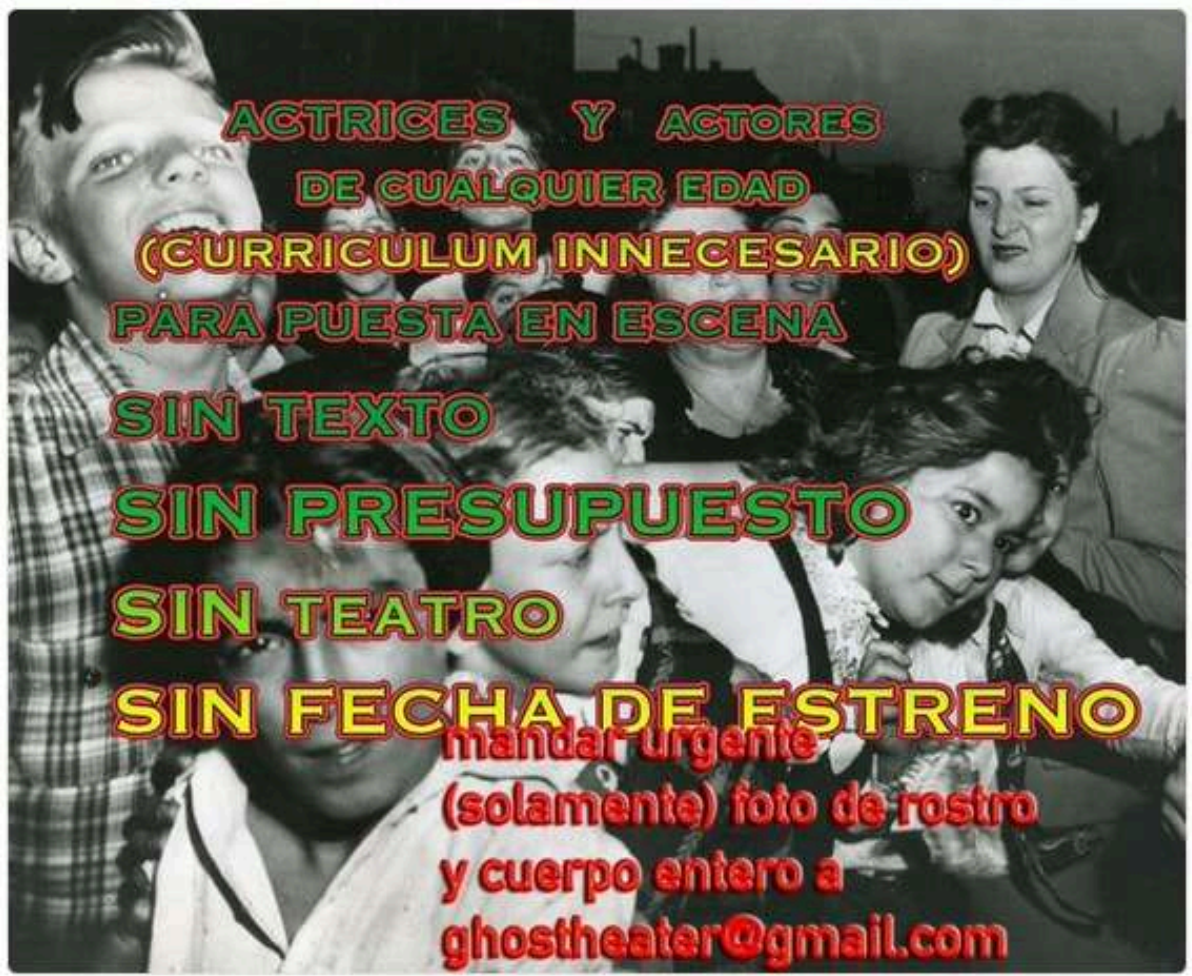

Convocatoria publicada en redes sociales.

9 De esta manera, nos dice José Antonio Cordero, se buscaba reflexionar sobre las maneras de hacer y de ofrecer teatro con actitud irreverente y escéptica a los programas públicos y privados que prevalecen en México.

El proyecto Madame Bovary (señora Vaca) toma forma de un manifiesto escénico en el cuál, a lo largo del proceso de creación, se fueron solicitando recursos a través de diferentes convocatorias públicas o privadas. La única consigna era que todo resultado favorable o desfavorable se iría añadiendo a la anécdota de la puesta en escena. El hecho de desvincularse de esta economía teatral y de los modos de producción del teatro mexicano, no querría decir que serían independientes de ello pues, como podremos ver se fueron pidiendo a lo largo del proceso diferentes apoyos.

Otra particularidad del proyecto es la manera en la que se cuantificaron los ingresos y las pérdidas. Se comenzaron a solicitar recursos de cualquier tipo de manera que, todas las aportaciones en especie, en trabajo - horas/hombre, conceptuales, afectivas etc., iban hacia un fondo de pérdida y en el caso de recibir patrocinios, coproducciones, compra de funciones, donativos, etc., se construía una tabla de ingresos positiva. Esta manera de exponer la necesidad de un trabajo, que podríamos decir gratuito, pone en evidencia los fallos del sistema de producción teatral, en el cual adoptar modos de producción sin remuneración se ha vuelto la norma y no la excepción. Los que podemos acentuar de esta metodología, de cuantificar los ingresos y las pérdidas, es que, en un principio, la calidad y la cantidad no son lo principal ni lo más importante, al menos no que la cualidad. De esta manera, cuantificando lo cualitativo, funciona como un mecanismo de denuncia mimética, el cual utiliza un lenguaje común a la institución en este caso una tabla presupuestal, pero de manera pervertida. 
12 Aquí podemos ver el desfase entre la institución y las necesidades del colectivo - el cual representa, a su vez, a otros colectivos, grupos y compañías teatrales - en cuestión de modos de producción y de lo que Howard S. Becker llama "El arte como actividad". Podemos decir que, para la institución, hay eslabones en la cadena del mundo del arte que resultan inexistentes o bien, que tienen que ir a cuenta de quienes quieren llevar a cabo un espectáculo.

13 De estos eslabones podemos ver que la concepción de la idea, las ejecuciones materiales, la formación necesaria para llevar a cabo la idea, las actividades de mantenimiento y refuerzo no entran dentro de los estatutos de ciertas convocatorias del FONCA. La mayor parte de los apoyos piden ya tener satisfechas estas necesidades antes de poder postular al financiamiento del espectáculo. Desde el punto de vista de la institución, esto puede ser necesario para evitar invertir en colectivos como el de Teatro sin teatro, es decir, un colectivo que cuenta únicamente con su entusiasmo en llevar a cabo un proyecto.

14 Podemos ver que las convocatorias de la institución cuentan con la misma función que la convocatoria lanzada por José Antonio Cordero, ser un filtro ideológico en el cual solamente las agrupaciones consolidadas puedan pasar por la coladera., Podemos decir hipotéticamente que, este filtro ideológico funciona como un estímulo para echar a andar la máquina del mundo del arte. Sin embargo, es valido preguntarnos si esto no resulta contraproducente para el arte mismo, imponiendo la forma y el contenido así como los modos de producción y de representación, restando lugares a nuevas maneras de crear y de llevar acabo un teatro sin teatro o - una escena expandida, como propone Rubén Ortiz ${ }^{3}$.

15 Hasta ahora, podemos ver cómo dispositivos de transgresión como la convocatoria y la tabla presupuestal, propuestos por José Antonio Cordero, tienen los mismos fines que aquellos propuestos por la institución. La diferencia es que uno funciona para denunciar y hacer evidente la necesidad de otras formas y el otro tiene como función el salvaguardar la institución y sus modos operativos. Una vez ya expuesto este mecanismo, nos resulta necesario hablar de lo que podríamos considerar como la substancia de los casos presentados, la del colectivo Teatro sin teatro y la del Fonca. Por substancia, nos vamos a referir al contenido de la obra Madame Bovary (Señora Vaca) y de lo que se dice en ella, de la representación teatral, en el caso del colectivo. En el caso de la institución, veremos rápidamente su razón de existir, sus bases y fundamentos, de esta manera podremos tener más claro a lo que nos referimos cuando hablamos de las representaciones e intentar esbozar una posible correlación entre ellas.

\section{Madame Bovary (Señora Vaca)}

16 En un documento que formaba parte de la carpeta realizada para el programa "Coinversiones" del FONCA del 2016, José Antonio Cordero expone su propuesta escénica. En el espectáculo Madame Bovary (Señora Vaca) se pretende denunciar la posibilidad de estar enfermo de capitalismo. Se hace resaltar la confusión del mundo contemporáneo del poseer personas como objetos, esto - nos dice José Antonio Cordero, se logra gracias a un dispositivo escénico en el cual todo fue creado de la nada y poco a poco se anhela y se necesita todo. 
Según la propuesta escénica del espectáculo, en este se mostrarían escenas clave de la novela de Flaubert, en las que se resalta el lado materialista de Emma Bovary. Para Mario Vargas Llosa en su obra La orgía perpetua, parafraseado por José Antonio Cordero, la imbricación entre el sexo y el dinero es lo que hace de Madame Bovary la primera novela de la modernidad. En el espectáculo, este materialismo, este capitalismo tiene sentido, pues todos los actores son y quieren ser Emma, todos narran la historia de Madame Bovary y a la vez la de su propio proyecto personal.

Cada uno de los actores va a explicar a los espectadores el porqué de su participación en este montaje. Dichas explicaciones o razones varían. Pueden partir de lo material como por ejemplo el hecho de poder comprarse un colchón o, ser por razones políticas como poder hablar de la opresión femenina o del poliamor y otras, pueden ser meramente para satisfacer una curiosidad. Estas razones tienen en común partir de algo personal, ambiguo, banal para unos, esencial para otros. De esta manera, el espectáculo ya no es sólo un espectáculo, ya no es cien por cien ficción. Podemos darnos cuenta de que de esta manera se expone también que no siempre se hacen las cosas sin desear algo a cambio, de manera egoísta, y que puede parecer, a veces, de manera banal tal como Emma Bovary.

19 José Antonio Cordero parte considerando a Madame Bovary de Flaubert, como la primera heroína enferma de capitalismo pues desea poseer no solo objetos, sino personas también. Esto desencadenará las características principales de dicha heroína. Basándose en lo que dice el meme de internet que circula en las redes sociales: "¿Se siente triste y deprimido? ¿ Sufre de ansiedad? ¿Esta preocupado por el avenir? ¿Se siente desolado y solo? Usted puede estar sufriendo de CAPITALISMO" (Ilustración 2), esta premisa será la piedra angular de su puesta en escena. El malestar, la angustia, la soledad que causa el hecho de desear todo.

En cuanto al subtítulo del espectáculo, Señora Vaca, podemos entender que se refiere al deseo carnal el cual - desde la mitología griega (Ío, Pasífae, Europa), se viene repitiendo y se lleva a cabo hasta las máximas consecuencias. 


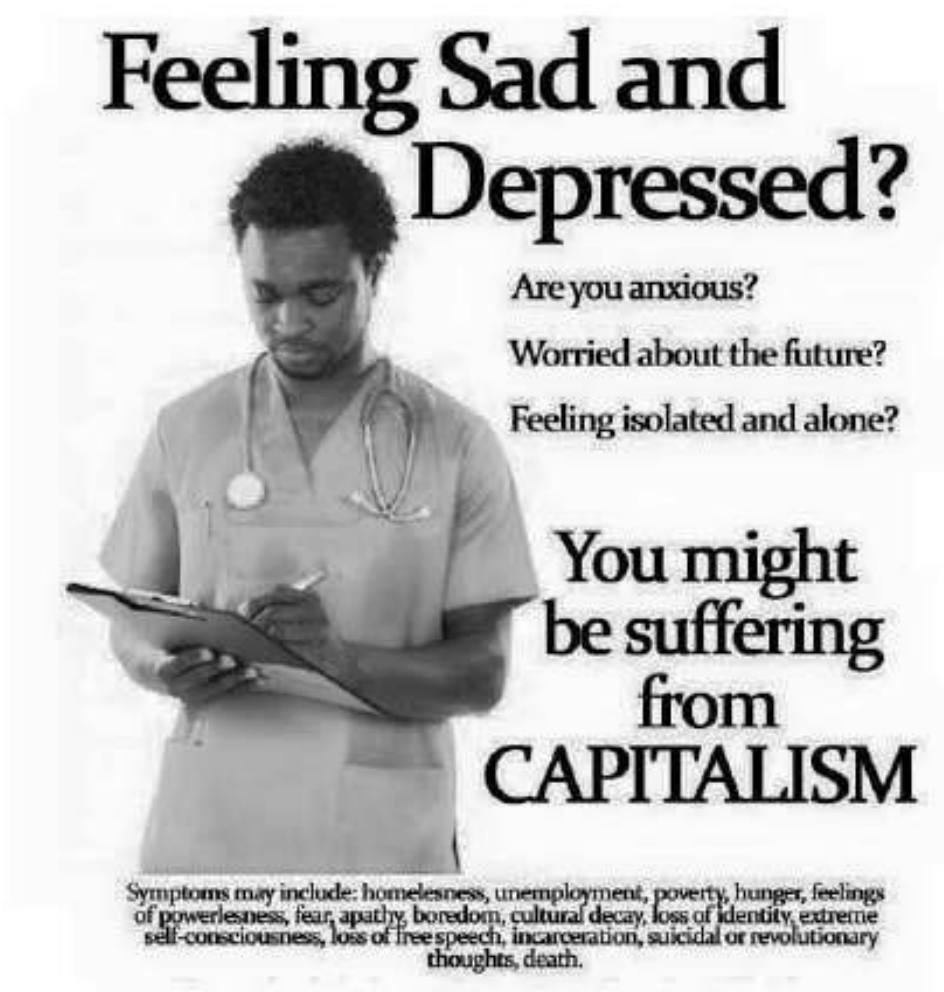

"Meme" de internet "Enfermo de Capitalismo"

21 En el espectáculo Madame Bovary (Señora Vaca) no solamente se denuncia el materialismo, sino también se exponen los modos de producción que existen en el teatro mexicano. No solamente pasando a ser un teatro de protesta o "engagé » sino construyendo la puesta en escena a manera de mosaico, de modo que este dispositivo forma un ensamble en el que cada cuadro que lo conforma nos habla de algo particular y a la vez, al tomar distancia, habla de un problema que se dirige a todos y a cada uno de los espectadores.

Podemos decir que este espectáculo es un buen ejemplo de a lo que Rancière llama un teatro sin espectador, el cual no es un espectáculo frente a butacas vacías, sino que el paradigma cambia cuando hay cuerpos en movimiento frente a cuerpos vivientes a movilizar. Los asistentes al espectáculo aprenden en lugar de solamente dejarse seducir por las imágenes, los espectadores son participantes activos en lugar de observadores pasivos. En el caso de Madame Bovary (Señora vaca) podríamos agregar que no sólo se busca movilizar y enseñar al espectador acerca de una situación social y de los modos de producción teatrales, también busca el diálogo, entre actores y público. Por ejemplo, al inicio de la obra preguntan al público: ¿ cuánto cuesta un actor? ¿cuánto cuesta una hora-persona? preguntas a la cual el público responde y debate. De esta manera podemos ver que en el público no existe una pasividad, pues es invitado a todo momento a debatir.

De esta forma, el espectador entra en lo privado de un grupo de personas que realizan un proyecto. En este caso, tres actrices, un actor, un diseñador de producción, un músico, una coreógrafa, un productor ejecutivo, una investigadora y un director/ dramaturgo/actor. El mecanismo de mostrar los entresijos hace o pretende hacer una toma de conciencia al espectador. Por un lado, le hace ver que su rol puede ser 
diferente de lo que comúnmente se piensa. En este caso, puede debatir, opinar, testimoniar y participar. Cosas que reivindican la diversión del fenómeno teatral. Por otro lado, podemos ver que este mecanismo puede ayudar a que el espectador se cuestione sobre la manera en la que consume teatro, sus expectativas y referencias, de modo que se pueda interrogar si eso que se está representando en escena realmente lo representa. De la misma manera en la que el colectivo podría preguntarse si la institución realmente los representa.

Edward Said, nos dice que: "hay que eliminar los sistemas de representación que portan en ellos un tipo de autoridad represiva, esos que no permiten que haya un espacio para que aquellos que están siendo representados puedan intervenir"4. Por ello, me resulta necesario cuestionar estas representaciones, de un lado la teatral y del otro la representación colectiva vuelta institución. Tal vez así podamos descifrar que fundamentalmente se encuentran ligadas.

\section{La crisis de las representaciones o las representaciones obsoletas}

Para poder combatir y eliminar a los sistemas de poder de representación, E. Said propone como alternativa el crear un "sistema de representación participativo, colaborativo y no coercitivo" 5 . Dicho esto, podemos hacer un contra punto con lo que mencionaba previamente con respecto al arte como actividad, y de la aparente inexistencia de ciertos eslabones para la institución. Justamente, esta alternativa colaborativa entre sus participantes es lo que dio origen al proyecto del colectivo Teatro sin teatro pero la colaboración entre institución y los colectivos parece ser mínima o inexistente.

Por actividad colectiva podemos referirnos a un estímulo a la creación, residencias artísticas, formaciones específicas para la realización de un proyecto, en fin, todo ello que conlleva el arte como actividad. Por el momento el apoyo que el FONCA otorga es económico. Si bien es una parte importante para el desarrollo de un proyecto, no es ni lo fundamental ni lo esencial.

Podemos reflexionar sobre la situación de compañías emergentes, y darnos cuenta de que lo que necesitan es un acompañamiento que no sea solamente de índole económica, sino también un acompañamiento para la inserción al circuito cultural, espacios asociativos de creación, etc., de manera que el estímulo ofrezca y otorgue un verdadero estímulo a la creación artística.

El sistema caduco al que nos referimos es consecuencia de los cimientos en los cuales se construyó el FONCA, a quienes estaban destinado los apoyos y la manera en la que los otorgaban. El Fondo Nacional para la Cultura y las Artes (FONCA) fue creado en 1989 con los objetivos de apoyar la creación, producción artística y cultural de calidad, promover y difundir la cultura, incrementar el acervo cultural, preservar y conservar el patrimonio cultural de la nación ${ }^{6}$. Dicha institución, nos dice la investigadora Patricia Chavero, se crea cuando varias voces de intelectuales, entre ellos Octavio Paz, se alzan y acusan al Estado de tener un carácter "controlado" (nacionalista) en cuestión de políticas culturales, y piden crear un órgano responsable y homogeneizador. La respuesta del gobierno fue la creación de un sistema "moderno" de becas dirigido a creadores intelectuales, jóvenes creadores, ejecutantes y a grupos artísticos ${ }^{7}$. Como 
podemos ver, la respuesta del gobierno fue, desde un principio, el apoyo económico, sin tener alguna propuesta alternativa al acompañamiento de compañías emergentes, grupos o colectivos que desearan crear. Esto trae como consecuencia un sistema de meritocracia y de competencia, a veces desleal, entre los creadores.

Patricia Chavero nos dice en sus observaciones generales de su investigación sobre la "Memoria del foro de políticas públicas relativas al sector teatro" 8 lo siguiente: 1. "La política cultural implementada por el CONACULTA ${ }^{9}$, en el caso de las artes escénicas, no responde a la realidad socioeconómica y política del país. 2. el sector artes escénicas no se puede someter a la ley de la oferta y la demanda. 3. La evaluación de las artes escénicas no se puede dar en términos de utilidad económica, se debe valorar la contribución al terreno de la creación artística y el impacto social. - Y hace remarcar que, Hoy como ayer, el principal productor de artes escénicas - en México - continúa siendo el Estado". Este tercer punto nos hace ver de qué manera el sistema de las representaciones sociales antes mencionadas (FONCA, CONACULTA) pueden convertirse en un poder represivo, incluso sin que su objetivo inicial sea ello. El factor represivo vendria como consecuencia de su construcción en base a estatutos y premisas válidas para los años noventa.

Estas bases pueden llevar al artista, creador, actor, productor, espacio/teatro, a continuar con este sistema estancado y a ejercer en base a una serie de preceptos, los cuales no lo dejan "ocupar" su terreno, de manera que podrían afirmar, como lo haría un colaborador de José Antonio Cordero, que el FONCA no los deja ser marginales.

Efectivamente, podemos resaltar que, incluso el hecho de querer salir del margen impuesto de los medios de producción, el FONCA no busca o no logra entender, hasta qué punto hay colectivos, compañías y grupos que desean cambiar los cimientos de dicha institución. $O$ bien, la institución intenta acaparar aquello que emerge para poder controlarla y meterla en regla.

Estas preguntas, no pueden ser completamente válidas sin antes aclarar las raíces de aquello que denuncia a la institución, en este caso el teatro. Sabemos desde Aristóteles que el teatro, es la representación de hombres en acción, también sabemos que una de sus características innatas es de ser una expresión política la cual refleja o responde lo que inquieta al oikos. De este modo podemos estar de acuerdo con Rubén Ortiz y afirmar que, si cada cultura implica un modo representativo, en México podríamos resumirlo de la siguiente manera: uno es capaz de representar a todos. Esto viene, naturalmente, de una legitimación de la autoridad dominante, la cual deviene una representación social. El sujeto que, por lo general, representa en México es de tipo "europeo, varón, blanco, adulto y heterosexual"10. Esta autoridad se vuelve represiva cuando aquellos que están siendo representados ya no se sienten legítimamente representados bajo ese modo de producción. Parafraseando al investigador Oscar Cornago, es una máquina descompuesta, con un mecanismo averiado y con una representación chirriante que gira sobre sí misma ${ }^{11}$. Con esta perspectiva, podemos decir al respecto del teatro en México, que la representación teatral se encuentra en crisis, siguiendo el razonamiento de Rubén Ortiz cuando nos dice que, en México, la palabra actuar es "sinónimo de 'representar" y, a su vez, representar aparece como una fuerza de la "identificación"12.

Sabemos que ésta mecánica viene a instaurarse en el teatro mexicano bajo la escuela del realismo y más precisamente de la escuela del método Stanislavski, introducido en México por Seki Sano en los años cuarenta. Sin embargo, en la comunidad teatral han comenzado a emerger grupos de artistas que, como nos lo explica Ileana Diéguez, citada 
por Ortiz, intentan tener otra relación con los referentes y esto debido a la crisis de los modos representacionales de operar ${ }^{13}$. Este problema se ha dado en el teatro pues este mismo, durante mucho tiempo, ha sido regido por el auto nombramiento de la mímesis como única manera válida de "hacer teatro". Ortiz comienza su reflexión de la siguiente manera:

Un ejemplo constante en nuestro teatro es la imposibilidad de poder dialogar acerca de nada que no se parezca a la puesta en escena costumbrista. He visto durante todo lo que va del siglo cómo ante cualquier manifestación de escena expandida, los críticos, los pedagogos, los artistas y quienes se mueven en el curso de las legitimaciones teatrales, cierran cualquier discusión con un: "i pero eso no es teatro!" 14

Basándonos en estas conjeturas, podemos deducir ver que coexisten dos maneras de definir lo que es o no es teatro, cosa que no es rara ni nueva. Esto se debe, tal vez, a la naturaleza y al origen aristotélico de estos conceptos los cuales, paradójicamente, nunca fueron definidos por él mismo. No son precisos y están basados principalmente en un tratado que explica la manera de escribir una tragedia y no de la puesta en escena teatral (de la opsis).

La imagen de la máquina chirriante que propone Cornago sirve para ejemplificar que el lubricante de esta representación es el modo representacional realista-costumbrista. Si, hipotéticamente, se desea cortocircuitar la institución - por retomar un término de Cornago, y al sistema representacional aristotélico, tendría que evidenciar su ineficacia frente a individuos que ya no sienten frente a esas representaciones, en las que ya no se ven reflejados, en las que el espejo se ha vuelto polvoriento y opaco.

Podemos decir que la toma de conciencia de lo obsoleto de la institución se encuentra latente. Sin embargo, Deleuze nos advierte que "La toma de conciencia es de una gran potencia, pero no está hecha para las soluciones, ni para las interpretaciones." ${ }^{15} \mathrm{En}$ resumen, no basta con el hecho de saber que las cosas están desajustadas, es el devenir y la acción, lo que llevará a cabo el cambio. El colectivo Teatro sin teatro intenta, y atenta ante la institución, no sólo advertirnos e invitarnos a tomar conciencia. Podemos decir que tomando en cuenta todo lo antes dicho, logra inmiscuirse en las entrañas del sistema que pretende representarlo para así "cortocircuitar" y hacer callar la máquina chirriante sin tener que continuar a aceitarla. ¿De qué manera? En primer lugar, el hecho de poder "cortocircuitar" el sistema, tiene como resultado el de poder ocupar terreno. Para que esta ocupación sea viable hay que habitarla y por supuesto, vivir en ella: la creación de Madame Bovary (Señora Vaca) se llevó a cabo en un espacio de residencia artística llamado Obrera centro. Lo interesante de este espacio es que existen estrechos actos de complicidad y de creación entre los participantes y los artistas, por ejemplo, cuenta con una cocina totalmente equipada y en cada evento invitan a un artista a cocinar y a dar una plática mientras conjetura algún platillo ${ }^{16}$. Entonces es, siguiendo las reflexiones de Cornago, cuando una nueva idea del artista surge, en la cual el artista, sí, es diferente pero también es uno más, uno cualquiera. De esta manera vemos que lo que propone E. Said se pone en práctica, pues existen dispositivos de participación entre el público y los artistas en residencia y colaborativos entre el espacio Obrera centro y los grupos que ahí se presentan.

37 En segundo lugar, como ya lo hemos visto, el nivel de exposición de dichas representaciones se vuelve cada vez más agudo. Por ejemplo, cuando durante el espectáculo los actores preguntan cómo sería y cuánto costaría hacer la puesta en escena si fuesen un grupo amateur o un grupo de teatro independiente, no subsidiado, 
o una institución gubernamental, o una producción privada o comercial, etc. A cada una de estas preguntas el productor y la investigadora Patricia Chavero (experta en procesos de producción, distribución y consumo de la cultura y las artes) intervienen y exponen la realidad de los sistemas de producción del teatro en México. Este tipo de intervenciones hacen que los espectadores tomen conciencia de aquello que se está denunciando, pues están basadas en datos concretos y reales, como estadísticas, financiamientos incongruentes a la situación. Se muestra, por ejemplo, el derroche de inversiones de la Secretaría de turismo para un espectáculo del Cirque du soleil.

En esta misma línea, José Antonio Cordero lanza otro dispositivo de exposición llamado TELEFONCA. Este dispositivo comienza cuando después de haber presentado un work in progres, el equipo decide postular a la convocatoria del "Programa de fomento a proyectos y coinversiones culturales" del FONCA en el mes de Julio del 2016. En la lista de los proyectos retenidos figuraba la obra Madame Bovary (Señora Vaca).

Entre los estatutos del programa "Fomentos y coinversiones" del FONCA, se estipula que "no se admitirán proyectos cuya propuesta sea únicamente para creación de obra" y que "todo proyecto a postular deberá tener una salida al público en un plazo máximo de 12 meses" ${ }^{" 17}$. La presentación se programó para el mes de enero del 2017 pero, unos días antes del estreno, los recursos no habían sido transferidos por el FONCA. El director José Antonio Cordero decide llamar a los funcionarios, grabar las conversaciones telefónicas e incluirlas en la obra (Ilustración 3).

Ilustración 3

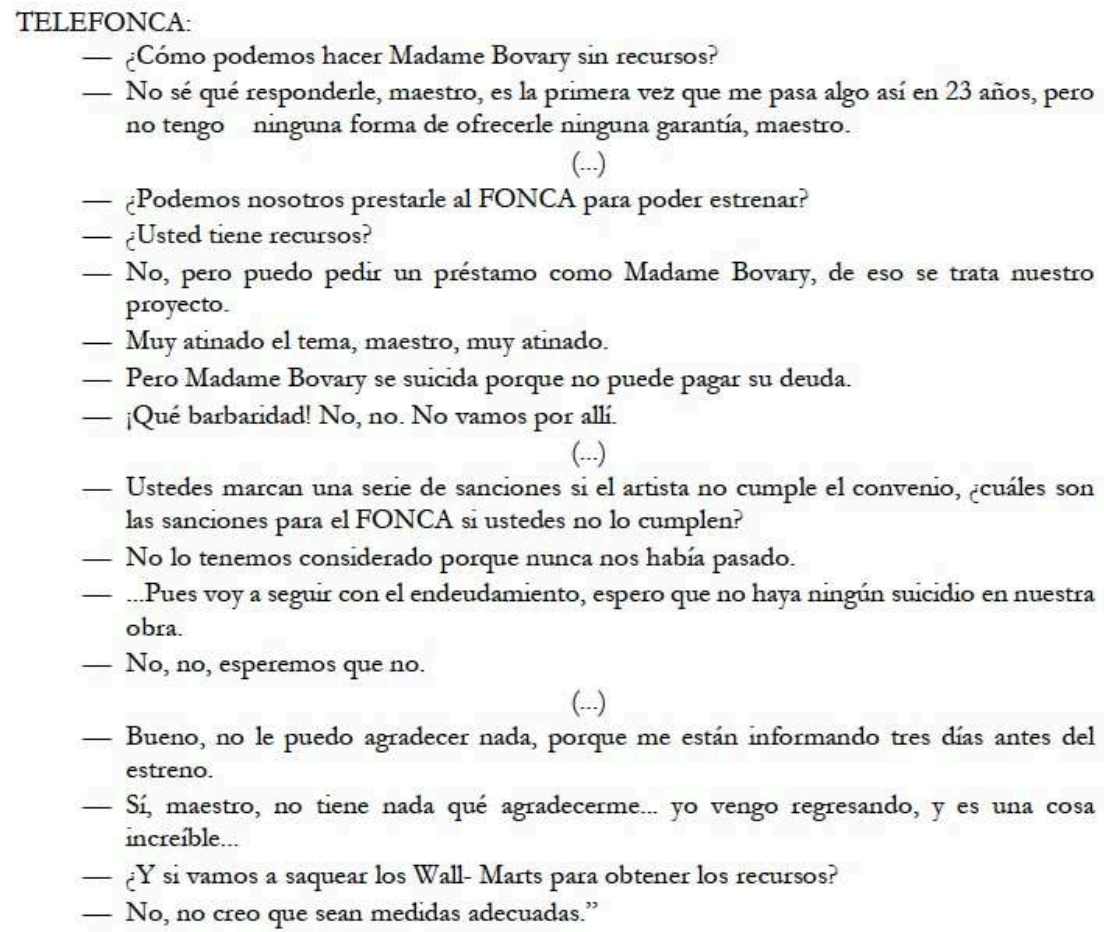

\section{"TELEFONCA"}

De esta forma, podemos darnos cuenta de que el dispositivo de exposición puesto en marcha desde un principio, con la convocatoria, siguió desarrollándose hasta formar parte del espectáculo. De manera que el discurso fuese congruente con la estética del 
espectáculo, la dramaturgia y el espacio en donde se crea. Esto nos lleva a reflexionar acerca de la correlación entre ambas representaciones. Podemos decir, gracias al ejemplo de este espectáculo, que hay una necesidad de que la representación teatral se multiplique, que se meta de acuerdo con aquellos que están siendo representados, en este caso los espectadores. Es necesario para la representación salir de esta crisis, pues si sigue de esta manera podemos predecir que la representación social - ahora institución, en este caso el FONCA, no cambiará tampoco y el sistema continuará siendo el mismo.

41 Pienso que si, como en el caso del colectivo Teatro sin teatro, no se les está permitiendo ser "marginales", a causa de la institución y sus mecanismos obsoletos, se podría reflexionar acerca de lo que Deleuze propone en este caso, y apostar a devenir “menores". Esta idea, viene de la conjetura que Carmelo Bene confía a Deleuze. Él cuenta que las personas a las que llamamos los "grandes hombres" son aquellos autores o artistas, que no se pueden ver fuera de su tiempo.

A lo que Carmelo Bene llama los autores "menores" son aquellos que crean las verdaderas obras maestras: "El autor menor no interpreta su tiempo, el hombre no tiene un tiempo determinado, el tiempo depende del hombre" ${ }^{18}$. Lo importante sería entonces, no el futuro o el pasado sino el devenir. Devenir aquí hay que entenderlo como hallarse presente, como suceder. Tener que oponerse a que el presente institucional rija los modos de producción y del arte como actividad; habría que dejar a un lado a los "grandes hombres" que fundaron la institución para así poder reformarla.

Para concluir, podemos decir que los dispositivos que el colectivo Teatro sin teatro utiliza, se inscriben en esta idea. No existe una interpretación de su tiempo, hay un tiempo presente, que sucede y sobrevive. El hecho de atacar y exponer a la institución con su propia metodología hace este corto circuito. Este corto circuito atrae un posible cambio de la institución desde el interior pues se ve reflejada y con la imposibilidad de combatirse a sí misma. De este modo la institución se expone, evidencia su petrificación, su punto débil y su obsolescencia. Cabe remarcar que no encuentro un afán por parte del colectivo Teatro sin teatro de hacer desaparecer la institución. Como ya lo mencionamos, lo que está en juego es el desfase y el no reconocimiento de esta representación colectiva.

Vemos que la compañía Teatro sin teatro, en esta creación en específico, no sólo denuncia, no sólo son artistas. También son lo otro, son los otros actores. El colectivo es Teatro sin teatro, pero también otros colectivos, se exponen en un devenir. Existen en una multiplicidad en forma de mosaico, como decíamos en un principio, en la cual no sólo se expone al FONCA sino a todo el sistema. No sólo se expone a los actores, directores, investigadores, productores y al público; no sólo se expone a los medios de producción teatral en México, ni solamente al consumismo, ni a la necesidad de poseer. Es un conjunto de teselas que a primera vista puede parecer sólo irreverente, pero si nos detenemos a ver el contenido de cada una de ellas todo puede recobrar sentido. Quizá de esta manera las cosas puedan cambiar. Quizá este modo de cortocircuitar el sistema haga del teatro, nuevamente, un útil de aprendizaje y de conocimiento. Parafraseando a Deleuze: es devenir, una manera quizás para que el teatro vuelva a ser un poder, un poder que, aunque critique al poder, pueda hacer algo, pueda ser un verdadero teatro revolucionario ${ }^{19}$. 


\section{NOTAS}

1. Edward Said, Dans l'ombre de l'Occident et autres propos, Paris, Payot \& Rivages, 2014, p. 15.

2. Para mas información acerca de "El arte como actividad" ver: Howard S. Becker Les Mondes de l'art, Paris, Flammarion, 2010, p. 28-32.

3. Para mas información sobre el concepto escena expandida ver: Rubén, Ortiz, Escena expandida. Teatralidades del siglo XXI, México D.F., Instituto Nacional de Bellas Artes y Literatura, 2015, p. 39.

4. Edward Said, Dans l'ombre de l'Occident et autres propos, op. cit., p. 15.

5. Ibid., p. 15.

6. Para más información referirse a: www.fonca.gob.mx/inicio/que-es-el-fonca.

7. Patricia Chavero, Memoria del foro de políticas públicas relativas al sector teatro, México D.F., CITRU, 2013, p. 17.

8. Ibid. p. 19.

9. El Consejo Nacional para la Cultura y las Artes, fundado en 1988, tiene como misión “de preservar de forma integral el patrimonio cultural de la Nación en sus diversas manifestaciones artísticas y culturales, así como estimular los programas orientados a la creación, desarrollo y esparcimiento de las mismas", para mas información ver: https://www.cultura.gob.mx/ acerca_de/.

10. Rubén Ortiz, Escena expandida. Teatralidades del siglo XXI, op. cit., p. 39.

11. Óscar Cornago, in "Teatro y poder: estrategias de representación en la escena contemporánea", Iberoamericana, Nueva época, n²1, 2006, p. 74.

12. Rubén Ortiz, op. cit. 2015, p. 29

13. Ibid.p. 11.

14. Ibid. p. 12.

15. Carmelo Bene et Deleuze et Gilles Deleuze, Superpositions, Paris, Les Éditions de minuit, 2016, p. 130.

16. Para más información referirse a: https://local.mx/cultura/arte/galeria/obrera-centro-lasmejores-piezas-se-conciben-en-la-cocina/.

17. http://fonca.cultura.gob.mx/wp-content/uploads/2017/06/

bases_fomento_coinversiones_2017.pdf.

18. Carmelo Bene et Gilles Deleuze, Superpositions, op. cit., p. 96.

19. Ibid., p. 131.

\section{RESÚMENES}

Edward Said, nos dice en su libro Dans l'ombre de l'occident et autres propos, que se tendrían que eliminar los sistemas de representación autoritarios y represivos, aquellos que no dejan espacio de intervenir a los que están siendo representados. En el teatro en México podemos ver que existen al menos dos modos de representación que se encuentran en crisis. Por un lado, la representación social que se ha vuelto institución y la cual rige los modos de producción en las artes escénicas y por otro lado la representación teatral, la cual desde los años cuarenta ha sido influida por el sistema estanislavskiano. En este articulo se expondrá la correlación entre la 
representación colectiva vuelta institución (FONCA) y la representación teatral. Esto lo ejemplificaremos con la creación del colectivo Teatro sin teatro y de su puesta en escena del espectáculo Madame Bovary (Señora Vaca), quienes, desde su génesis, hasta su propuesta teatral, desarrollan un dispositivo de exposición de los modos de producción ya caducos de dicha institución. Esto nos llevara a reflexionar acerca de dicha caducidad y de las posibles maneras de combatirla.

Edward Saïd propose dans son livre Dans l'ombre de l'occident et autres propos, d'éliminer les systèmes de représentation autoritaires et répressifs, qui ne laissent pas d'espace pour intervenir à ceux qui sont représentés. Dans le théâtre mexicain, nous pouvons constater au moins deux formes de représentation qui se trouvent en crise. D'un côté, la représentation sociale, devenue une institution qui règle les modes de production dans les arts scéniques. De l'autre, la représentation théâtrale, laquelle depuis les années quarante, a été influencée par le système stanislavskien. Sur cet article, nous allons exposer la corrélation entre la représentation collective devenue une institution (FONCA) et la représentation théâtrale. Ceci, nous allons l'exemplifier avec la création du collectif Teatro sin Teatro et de la mise en scène de son spectacle Madame Bovary (Señora Vaca), lesquels dès sa genèse jusqu'à sa proposition théâtrale, ils développent un dispositif d'exposition des modes de production caducs de l'institution. Cela va nous amener à réfléchir sur la péremption de l'institution et des possibilités de la combattre.

\section{ÍNDICE}

Mots-clés: représentations sociales, collectif artistique, théâtre, Mexique, représentation théâtrale, théâtre engagé, teatro sin teatro, FONCA

Palabras claves: representaciones sociales, colectivo artístico, teatro, México, representación teatral, teatro político, teatro sin teatro, FONCA

\section{AUTOR}

\section{VÍCTOR GABRIEL VILLANUEVA PÉREZ}

Universidad Sorbonne Nouvelle Paris III 